\title{
Prevalence of Urinary Tract Infection among Children Attending Babban Mutum Science Primary School Shekal, Bauchi State, Nigeria
}

\author{
I. A. Allamin'1, I. B. Machina², M. Ibn Abbas'1, K. I. Angale1 \\ ${ }^{1}$ Department of Microbiology, University of Maiduguri, Maiduguri, Nigeria \\ ${ }^{2}$ Kaatsinaliason Office, National Institute of Trypanosomiasis Research, Kaduna, Nigeria \\ Email: ibnallamin@gmail.com, ibnallaminmcb@unimaid.edu.ng
}

Received 31 May 2015; accepted 19 June 2015; published 26 June 2015

Copyright (C) 2015 by authors and OALib.

This work is licensed under the Creative Commons Attribution International License (CC BY). http://creativecommons.org/licenses/by/4.0/

(c) (i) Open Access

\section{Abstract}

The study was conducted to determine the prevalence of Urinary Tract Infection among children attending Babban Mutum Science Primary School Shekal, Bauchi State, Nigeria. The study was carried out between May to July 2014. Among apparently healthy pupils, a questionnaire was administered to determine the risk factors from different age groups, sex, and bed wetting history. One hundred (100) clean-catch urine samples were obtained from the pupils using standard procedures. Microbial culture on Cystein Lactose Electrolyte Deficient (CLED) ager and subsequent Biochemical tests revealed that Eschericia coli $(E$. coli) with $11(28.9 \%)$ was the most prevalent while Staphylococcus aureus with $2(5.3 \%)$ was the least prevalent of the samples with significant bacterial growth ( $\left.\geq 10^{5} \mathrm{CFU} / \mathrm{ml}\right) .38$ isolates were obtained out of which Gram negative bacteria were the most isolated. The in-vitro antibiotic resistance pattern of the isolates to common antimicrobial agents shows that the isolates are susceptible to all the antibiotics except Amoxycilline which is shown to be less effective in showing great sensitivity.

\section{Keywords}

UTI, Prevalence, Children, and Urine

Subject Areas: Microbiology

\section{Introduction}

Urinary Tract Infection (UTI) is an infection of the Urethra, Bladder and Kidney that comprises the urinary tract system of the body. Urinary Tract Infection can be defined as the presence of significant quantity or number of bacteria and other parasites in the urine along with signs and symptoms of infection [1]. The Urinary Tract In-

How to cite this paper: Allamin, I.A., Machina, I.B., Ibn Abbas, M. and Angale, K.I. (2015) Prevalence of Urinary Tract Infection among Children Attending Babban Mutum Science Primary School Shekal, Bauchi State, Nigeria. Open Access Library Journal, 2: e1596. http://dx.doi.org/10.4236/oalib.1101596 
fection in children is particularly important because their occurrence can be associated with some congenital abnormality of the Urinary Tract or an error in the management and if not corrected very early, may lead to recurrent infection causing damage to the urinary tract. These infections have been reported to be one of the most infections that cause serious health problems affecting millions of people both in the community and hospital setting [1].

Bacteria are the most common cause of Urinary Tract Infection and the most common clinical problems in childhood. Normally, bacteria that enter the urinary tract are rapidly removed by the body before they cause any symptoms. The bladder is normally sterile, completely free of bacteria and other infectious organisms. When an infection occurs, it is typically found in either the lower urinary tract affecting the bladder as well as the urethra, or the upper urinary tract which affects the kidney and the ureter. When an organism invades the urinary tract, it enters by one of these two routes: the lower end of the urinary tract or through the blood stream [2].

The bacterium, Eschericia coli which is part of the flora of the body is responsible for most of the reported urinary tract infections especially primary school children and or normal school age children. Eschericia coli is normally harmless in the small intestine where it normally resides and becomes a problem when it spreads to the urinary tract.

Urinary Tract Infection may be accompanied by "Dysuria”, “Cystic and Pyelonephrities” [3]. Urinary Tract Infections in so many cases may be asymptomatic while for some other cases, show signs such as high also the inability to and loose bowel movement. The Urinary Tract Infections are distributed in all age group in both sexes which are asymptomatic in most cases. Urinary Tract Infection in children is associated with abnormality of the urinary tract or an error in management which if not properly checked or corrected, may leads to recurrent infections thereby causing damage to the urinary tract.

This study aimed to identify the presence of unnoticed UTI among apparently healthy children attending primary school in Shekal. This is with a view to providing information that is lacking or unavailable in the literature from the sampled population.

\section{Materials and Methods}

The study area was conducted in Shekal area of Bauchi local government in Bauchi State, Northeastern Nigeria. Children that are apparently healthy and attending primary school (5 - 14 years) were selected for this study. Babammtum Science primary school was selected, from which a total of 100 samples were obtained. Equal numbers of samples were collected from both males and females. Pupils who participated in the study were selected at random. The inclusion criterion was children attending primary schools only, while the exclusion criteria were children below or above primary school age and those that had recently used antibiotics.

\subsection{Questionnaire}

A questionnaire was used to generate some data for this study. Questionnaires were sent to parent or guardian of all the participating children. The key area addressed in the questionnaire was recent use of antibiotics, age, sex, nocturnal enuresis (bedwetting) and previous history of UTI.

\subsection{Sample Collection}

Urine sample was collected from a total number of 100 pupils between the ages of 4 - 18 from primary $1-6$. Clean voided mid-stream urine sample was obtained in a sterile universal container from pupil who were instructed on how to collect the sample to prevent the isolation of normal flora and contaminant, the samples were kept in an ice chest and transported to the laboratory for further analysis. All the samples were analysed within 24 hours to ensure proper isolation.

\subsection{Urine Microscopy}

The wet preparation method was used for the urine microscopy examination. $10 \mathrm{mls}$ of well-mixed urine sample was transferred aseptically into a tube and spun in a centrifuge machine to separate the supernatant and the sediments. The sediment was well mixed by tapping the bottom of the tube, a drop of the mixed sediment was transferred to a slide and covered with a cover slip, then examined using $\times 10$ and $\times 40$ objective lens.

The sampled urine was well mixed to ensure even distribution of all microorganisms present in urine and us- 
ing a well sterilized wire loop. A loopful of the fresh urine was inoculated into CLED (Cystine Lactose Electrolyte-Deficient) Agar; it was incubated aerobically at $37^{\circ} \mathrm{C}$ overnight. Plates with growth were selected and the colonies were isolated using inoculating loops and subsequently sub cultured on agar slants for use in further tests [4]. Biochemical tests to identify individual organism were conducted from plates with positive result as described by [5], Antibiotic Susceptibility Test As Described By Kirby-Bauer Technique.

\section{Results and Discussions}

A total number of 100 urine samples were collected from different age groups of school pupils of which 50 samples each from both males and females were collected. Table 1 shows that of the 24 pupils between the ages of $4-6,12$ were found to be positive of with $50 \%$ positive, so also $20.8 \%$ of the 24 pupils between 7 - 9 years were positive, $36.4 \%$ of the 33 pupils between the age of 10 - 12 were also positive, $56.3 \%$ of the 16 pupils between 13 - 15 years were also positive of UTI. 3 pupils 16 - 18 years were found to be Negative. The result of shows that out the 50 male pupils 15 are positive giving $30 \%$ while 23 female are positive out of 50 female which also gives $46 \%$. Bedwetting shows 48 whom bed wet and 26 are positive with $54.2 \%$ while 52 whom are not bed wetting had 12 positive with 23.1\% (Table 1). Of the 38 isolates obtained, Gram negative bacteria were the most isolated and Eschericia coli (E. coli) with 11 (28.9\%) was the most prevalent while Staphylococcus aureus with 2 (5.3\%) was the least prevalent (Table 2). The in-vitro antibiotic resistance pattern of the isolates to common antimicrobial agents is shown in (Table 3).

The prevalence rate of UTI among children in primary school was found to be high in female between the ages of $4-18$, reveals $95 \%$ significant gender difference. The result of this study reveals the higher incidence of Urinary Tract Infections (UTI) in females as indicated in Table 1 is as a result of variety of factors such as most importantly Close Proximity of the female Urethra to the anus [6], as well as incomplete and inordinate voiding

Table 1. Distribution of UTI in relation to risk factors.

\begin{tabular}{cccc}
\hline Risk factors & Total & Positive & \% of positive \\
\hline Age & & & $50 \%$ \\
$4-6$ & 24 & 12 & $20.8 \%$ \\
$7-9$ & 24 & 5 & $36.4 \%$ \\
$10-12$ & 33 & 9 & $56.3 \%$ \\
$13-15$ & 16 & - & $-30 \%$ \\
$16-18$ & 3 & 15 & $46 \%$ \\
Sex & & 23 & $54.2 \%$ \\
Male & 50 & & $23.1 \%$ \\
Female & 50 & 26 & 12 \\
Bed wetting & & & \\
Yes & 48 & & \\
No & 52 & & \\
\hline
\end{tabular}

Table 2. Bacterial isolates isolated and identified in urine samples.

$\begin{array}{ccc}\text { Identified organisms } & \text { Occurrence } & \text { Total \% } \\ \text { E. coli } & 11 & 11(28.9) \\ \text { Pseudomonas sp. } & 5 & 5(13.2) \\ \text { Proteus sp. } & 3 & 3(7.9) \\ \text { Enterobacter sp. } & 9 & 9(23.7) \\ \text { Klebsiella sp. } & 8 & 8(21.1) \\ \text { Staphylococcus sp. } & 2 & \mathbf{2}(5.3) \\ \text { Total } & \mathbf{1 5} & \mathbf{3 8}(\mathbf{1 0 0})\end{array}$


Table 3. Number and percent (\%) of in-vitro antimicrobial resistance spectrum of isolates.

\begin{tabular}{|c|c|c|c|c|c|c|c|c|c|}
\hline Isolates & $\begin{array}{l}\text { No of } \\
\text { isolates }\end{array}$ & AUG & OFL & GEN & NAL & NIT & COT & AMX & TET \\
\hline E. coli & 11 & $10(9.1)$ & $11(0)$ & $10(9.1)$ & 8 (27.3) & $6(45.5)$ & $6(45.5)$ & 1 (90.9) & $9(18.2)$ \\
\hline Pseudomonas sp. & 5 & $2(60)$ & $3(40)$ & $4(20)$ & $4(20)$ & $2(60)$ & $1(80)$ & $1(80)$ & $3(40)$ \\
\hline Proteus sp. & 3 & 0 & $3(0)$ & $3(0)$ & $3(0)$ & $3(0)$ & 0 & 0 & $3(0)$ \\
\hline Enterobacter sp. & 9 & $2(77.8)$ & $8(11.1)$ & $5(44.4)$ & $5(44.4)$ & $3(66.7)$ & 1 (88.9) & 1 (88.9) & $6(33.3)$ \\
\hline Klebsiella sp. & 8 & $3(62.5)$ & $8(0)$ & $5(37.5)$ & $5(37.5)$ & $1(87.5)$ & 0 & 0 & 5 (37.5) \\
\hline $\begin{array}{c}\text { Staphylococcus } \\
\text { aureus }\end{array}$ & 2 & $2(0)$ & $2(0)$ & $2(0)$ & $2(0)$ & $2(0)$ & $1(50)$ & 0 & 0 \\
\hline Total & 38 & $19(50)$ & 35 (7.9) & 27 (28.9) & 27 (28.9) & 17 (55.3) & $9(76.3)$ & $3(92.1)$ & 26 (31.6) \\
\hline
\end{tabular}

AUG = Augmentin $30 \mu \mathrm{g}, \mathrm{NIT}=$ Nitrofurantoin $200 \mu \mathrm{g}$; OFL = Ofloxacin $5 \mu \mathrm{g}$; COT = Cotrimoxazole $25 \mu \mathrm{g}$; GEN = Gentamincin $10 \mu \mathrm{g}$; AMX = Amoxycillin $25 \mu \mathrm{g}$; NAL $=$ Nalidixic acid $30 \mu \mathrm{g}$; TET $=$ Tetracycline $25 \mu$.

of urine of school girls of which is often associated with constipation and encourages infections of the urinary tract [7], of the total number of 38 isolates were obtained from 38 pupils with positive urine cultures only one bacterial specie was isolated from each patient, suggesting a mono-microbial nature of infection in the study population. Thirty eight (38) isolates were made of six different organisms, these organisms are Eschericiacoli, Pseudomona species, Proteus sp., Enterobacter species, Klebsiella species and Staphylococcus aureus. E. coli was the most common organism isolated from 11 (28.9\%), followed by Enterobacterspecies 9 (23.7\%), Pseudomonas species 5 (13.2\%), Proteus mirabilis 3 (7.9\%) and Staphylococcus aureus 2 (5.3\%). The pattern and frequency of occurrence of the bacterial isolates found in this study is similar to those reported by authors who indicated that a Gram negative bacterium, particularly E. coli is the most common pathogen isolated in children with UTI [2]. The antibiotic resistance pattern of this study shows that Amoxycilline was the most poorly effective antibiotic against majority of the organisms isolated in this study. Increasing antibiotic resistance among urinary tract isolates (mostly against Amoxycilline) has been reported from many countries. The resistance rates from Amoxycilline were found to be $45 \%, 50 \%$ and $100 \%$ in children from Canada, Europe and Africa respectively [7]. However, the most effective antibiotic discovered in this study is Ofloxacin which have a resistance rate of $7.9 \%$, followed by Gentamincin which is also discovered to be very effective against the isolated pathogens. Similar results with Ofloxacin and Gentamincin have also been reported by other authors. This low resistance rate of pathogens is attributed to the fact that Ofloxacin and Gentamincin are relatively new antibiotics and have not been extensively used or they are relatively expensive when compared to those most frequently used ones. This probably had restricted their procurement and indiscriminate use, thereby making the organism susceptible to them. This report is also similar to the reports by [6] and [8].

\section{Conclusion}

The study shows a significant difference among children of age 4 - 6 years old and 13 - 15 years which is indicative that children of age group 4 - 15 are vulnerable and no significance difference between male and female sexes with a significant difference among pupils with bed wetting history. Since Urinary Tract infection (UTI) may be asymptomatic in most cases, it is therefore necessary that routine screening of school going children should be done for Urinary Tract Infection and that appropriate antimicrobials be administered after sensitivity tests have been carried out in order to prevent rampant cases of developing symptoms later, which result in renal damage.

\section{References}

[1] Abdulhadi, S.K., Yashua, A.H. and Uba, A. (2008) Organisms Causing Urinary Tract Infections in Paediatric Patients. Journal of Biomedical Health Sciences, 4, 165-167.

[2] Kolawole, A.S., Kolawole, O.M., Kandaki-Olukemi, Y.T. and Babatunde, S.K. (2009) Prevalence of Urinary Tract Infection and Adolescent in Ile-Ife, Nigeria. African Journal of Microbiology Research, 1, 13-19. 
[3] Karaou, K.M. and Hana, A (1981) An Epidemiologic Study of Urinary Infections in Beighazi, Libya. Journal of Hygiene and Epidemiologic, 25, 277-285.

[4] Isa, M.A., Ismail, H.Y., Allamin, I.A., Shettima, A. and Mustafa, A. (2013) Prevalence of Urinary Tract Infection among Primary School Children in Maiduguri, Borno State, Nigeria. International Journal of Environment, 2, 9-15. http://dx.doi.org/10.3126/ije.v2i1.9203

[5] Cheesbough, M. (2002) District Laboratory Practice of Tropical Countries. Cambridge, New York.

[6] Ebie, M., Kandoki-Olokemi, Y.T., Ayabadejo, J. and Tanyigna, K.B. (2001) Urinary Tract Infections in Nigerian Military Hospitals. Nigerian Journal of Microbiology, 15, 31-37.

[7] Anochie, I.C., Nknankinieme, K.E.O. and Ekie, F.U. (2003) The Influence of Instruction about the Method of Urine Collections and Storage on the Prevalence of Urinary Tract. Nigerian Journal of Paediatric, 28, 39-42.

[8] Ehinmidu, J.O. (2003) Antibiotic Susceptibility Pattern of Urine Bacterial Isolates in Zaria, Nigerian. Tropical Journal of Pharmaceutical Resources, 2, 223-228. 